\title{
Başkurtçayla Tanıklanabilen Eski Türkçe Hapaxlar
}

\section{Old Turkic Hapaxes That Can Be Attested to in Bashkir}

\author{
Hülya Y $11 d 1 z^{1}$ (i)
}

'Doktor Öğr. Üyesi, Anadolu Üniversitesi, Edebiyat Fakültesi, Türk Dili ve Edebiyatı Bölümü, Eskişehir, Türkiye

ORCID: H.Y. 0000-0002-1496-1617

Sorumlu yazar/Corresponding author: Hülya Yıldız,

Anadolu Üniversitesi, Edebiyat Fakültesi, Türk Dili ve Edebiyatı Bölümü, Eskişehir, Türkiye

E-mail: hkoprulu@anadolu.edu.tr

Başvuru/Submitted: 02.08.2021

Revizyon Talebi/Revision Requested: 08.11.2021 Son Revizyon/Last Revision Received: 26.11.2021 Kabul/Accepted: 02.12.2021

Online Yayın/Published Online: 14.12.2021

\section{Atıf/Citation:}

Yildiz, H. (2021). Başkurtçayla Tanıklanabilen Eski Türkçe Hapaxlar. TUDED, 61(2), 747-762. https://doi.org/10.26650/TUDED2021-977802

\section{ÖZET}

Türk dil ailesinin Kıpçak grubuna ait ayrıksı bir dil olan Başkurtça, anlambilimi, söz varlığı ve söz yapımı bakımından hem Kıpçak grubuna hem de diğer Türk dillerine kıyasla kimi eskicil ögeler barındırır. Söz varlığı açısından bakıldığında, günümüz Türk dillerinde kullanımdan düşmüş bulunan çok sayıda Eski Türkçe sözcüğün eskicil anlamlarını koruyarak Başkurtçada varlığını sürdürdüğü görülmektedir. Eski Türkçenin söz varlığının neredeyse dörtte biri hapaxlardan oluşur. Bu makale Eski Türkçe metinlerde hapax olarak geçen Türkçe söz varlığı ile Başkurtçanın söZ varlığını karşılaştırmak amacıyla yazılmıştır. İncelemenin sonucunda, 32 Eski Türkçe hapaxın Başkurtçada hâlâ varlığını sürdürdüğü gösterilmiştir. Makalede ele alınacak Eski Türkçe hapaxlar bagırlan-, bıçış-, bürçäklän-, bürgälän-, ärsäklän-, ätlä-, ıtla-, isiglä-, kadışla-, karlan-, käçtür-, kıdıgla-, kutan-, küglän- I, küzä-, örüm, talagu, tarmaklan-, tartışlıg, tayış-, tämürlük, tişät-, tüplän-, tüplät-, tüşlük, üklüş-, yazlat-, yemsin-, yersin-, yetizlik, yıgım, yıglış- ve yunçıt- sözcükleridir. Çalışma üç bölüm olarak tasarlanmıştır: Giriş bölümünde hapax terimi, Başkurtça ve makalenin düzenlenişi üzerine kısaca bilgi verilmektedir. İkinci bölümde Başkurtça ile yapılan karşılaştırma sonucunda hapax olma niteliğini yitiren 32 Eski Türkçe sözcük ele alınmaktır. Üçüncü bölüm ise elde edilen bulguların özetlendiği Sonuç bölümüdür.

Anahtar Kelimeler: Hapax, Başkurtça, etimoloji, Eski Türkçe, Kaşgarlı Mahmut

\section{ABSTRACT}

Bashkir, a distinctive language belonging to the Kipchak group of the Turkic language family, has some archaic elements in terms of its semantics, vocabulary, and word formation compared to other Turkic languages. Many Old Turkic lexemes still survive in Bashkir, preserving their archaic meanings. Almost a quarter of the vocabulary of Old Turkic consists of hapaxes. This article will compare the Old Turkic hapaxes and the Bashkir vocabulary. The results of the study show that 32 Old Turkic hapaxes still exist in Bashkir. The Old Turkic hapaxes that will be dealt with here are bagırlan-, bıçış-, bürçäklän-, bürgälän-, ärsäklän-, ätlä-, ıtla-, isiglä-, kadışla-, karlan-, käçtür-, kıdıgla-, kutan-, küglän-I, küzä-, örüm, talagu, tarmaklan-, tartışlıg, tayış-, tämürlük, tişät-, tüplän-, tüplät-, tüşlük, üklüş-, yazlat-, yemsin-, yersin-, yetizlik, yıgım, yıglış-, and yunçıt. The paper is organized as follows: Brief information is given about the term hapax and Bashkir in Section 1, Introduction. In Section 2, a total of 32 hapaxes are discussed. Finally, the lessons drawn from these findings are summarized in Section 3, Conclusion.

Keywords: Hapax, Bashkir, etymology, Old Turkic, Kashgarî 


\section{EXTENDED ABSTRACT}

Hapax legomena, sometimes abbreviated to hapax, is a word or an expression that occurs only once within a context: either in the written record of an entire language, in the works of an author, or in a single text. In Turcology, the term is widely used by Clauson in his Etymological Dictionary (1972). Almost a quarter of the vocabulary of Old Turkic (nearly 2250 items) consists of very rare data occurring only once in the whole Old Turkic corpus. These words have not been discovered elsewhere and are, in other words, hapaxes. However, Clauson himself states that some of these kinds of words may be discovered elsewhere in the future.

Bashkir, a distinctive language belonging to the Kipchak group of the Turkic language family, has some archaic elements in terms of semantics, vocabulary, and word formation compared to both its own group and other Turkic languages. In terms of vocabulary, many Old Turkic lexemes, which have fallen out of use in today's Turkic languages, survive in Bashkir, preserving their archaic meanings.

The present paper aims to compare Old Turkic hapaxes occurring in Clauson's Etymological Dictionary with Bashkir. The main criterion for choosing Bashkir for this comparison is that the Bashkir vocabulary is an untouched area within comparative vocabulary studies between old and modern Turkic languages. The results of the study show that the Old Turkic lexemes bagırlan- "(for blood, sour milk) to coagulate and become solid," bıçıs- "to compete or to help someone in cutting," bürçäklän- "to grow a forelock," bürgälän- "to jump with rage as if one were a flea," ärsäklän- "to look for a man because of her passionate desires," ätlä- "to fatten," itla- "to reckon someone to belong to the dog family," isiglä- "to walk in the summer heat," kadışla- "to cut a strap in a strip," karlan- "to be full of snow," käçtür- "to order someone to cross the water," kldigla- "to sew a brim," küglän- I "to sing," küzä- "to spend the autumn," örüm "something plaited or wowen," talagu "a quick-acting poison; dysentery," tarmaklan"to settle like claws in every direction; to grow claws; (for water) to form channels," tartışlıg "(something) which drag a man," taylş- "to compete with someone in sliding," tämürlük "a place at which iron-stone is melted and iron is refined from it," tişät- "to order the teeth of the sickle to be sharpened," tüplän- "to take root," tüplät- "to have something thoroughly investigated," tüşlük "a halt for a rest," üklüş- "to be piled on another," yazlat- "to put someone for the spring on the summer pasture," yemsin- "to pretend to eat the food," yersin- "to become accustomed to a place," yetizlik "width, breadth," yı gım "a heap of something," yılglş- "to come together," and yunçıt- "to do evil to someone, to harm," indeed survive in the vocabulary of Bashkir although they were qualified as hapaxes by Clauson (1972) in his Etymological Dictionary.

The above-mentioned lexemes, of course, underwent some phonological and/or semantic developments in Bashkir over the course of time. The modern Bashkir forms of the abovementioned hapaxes are as follows, respectively: bavirlan- "(for blood, sour milk) to coagulate and become solid," bısış- "to saw together," börsöklen- "to bubble up, granulate," birělen- "to rage, go mad with anger," irheklen- "to coquet, flirt," itle- "to join and sew the leather," itla- "to torture, torment," ésèle- "to be affected by the warm weather; to heat," kayışla- "to hit with a 
belt, strap on," karlan- "to be covered in snow," kistěr- "to have someone to cross something," klyıvla- "to stripe, to line; to brace," köylen- "to be sung; to be in harmony; to be convinced," köźe- "to trim the tails of foals in spring; to shave," ürěm "something plaited, knit, braid," talav "painful swelling in animals such as cattle, sheep," tarmaklan- "to branch, branch out," tartışll "contentious," taylş- "to deviate, to be inclined," timěrlěk "forge," těşet- "to sharpen the teeth of tools," töplän- "to settle down, take root," töplät- "to make bottoms on things such as buckets, baskets; to make sole for a shoe," töşlök "south; noon; lunch; the summit of the rising sun," öyölöş- "to be piled on other," yaźlat- "to have someone/something spent the spring," yěmhěn- "to forage, search for food," yěrhěn- "to get used to a place," yětěźlék "lenght, extent," yıyım "collecting, tax, crop," yıyılış- "to be piled on other," and yonsot- "to tire, to torture".

In the present article, the author also touches upon phonological and semantic developments of Bashkir forms. The paper is organized as follows: Brief information is given about the term hapax and Bashkir in Section 1, Introduction. In Section 2, a total of 32 words that lost the quality of being hapaxes as the result of the comparison between Old Turkic and Bashkir are discussed. Finally, the lessons drawn from these findings are summarized in Section 3, Conclusion. 


\section{GİRIŞ}

Hapax legomena ya da kısaca hapax, bir bağlamda yalnızca bir kez geçen bir kelime veya ifadedir. Bu bağlam bütün bir dilin yazılı kayıtları olabileceği gibi bir yazarın eserleri ya da tek bir metin de olabilir. Türkolojide bu terim, Gerard Clauson'un VIII.-XIII. yüzyıllar arasına tarihlenen Eski Türkçe metinlerin söz varlığını kapsayan An Etymological Dictionary of PreThirteenth Century Turkish (ED) adlı eserinde yaygın olarak kullanılmaktadır. Bu eserdeki madde başlarının neredeyse dörtte biri ${ }^{1}$, Clauson'un hapax kaydını düştüğü verilerden oluşmaktadır.

Adından da anlaşıldığı üzere, Etimolojik Sözlük temelde XIII. yy. öncesi Türk yazı dillerinin sözlüğüdür. Buna rağmen bu çalışma, XIII. yy. öncesi malzemenin hem XIII. yy. sonrası tarihi yazı dilleriyle hem de sözlükler başta olmak üzere çağdaş Türk dilleri alanında 1970'lere kadar yayımlanan yetkin kaynaklarla karşılaştırıldığ 1 çok kapsamlı bir veri tabanıdır. Ancak sözlükte hapax terimiyle ilgili bilgi çok sınırlı olup sadece 'occuring only once' (Clauson, 1972, s. xxxiv) yani 'bir kez geçen' şeklinde bir açıklama yapılmış; bu ibareyle verilen sözcüklerin bütün bir dilin yazılı kayıtlarında mı bir yazarın eserlerinde mi yoksa bir metinde mi tek örnek olarak yer aldığı açıkça ifade edilmemiştir. Yine de sözlükteki madde başları dikkatle incelendiğinde, Clauson'un hapax terimini bir yazarın eserleri ya da bir metinde bir kere geçen veriler için değil; VIII.-XIII. yüzyıllar arasına tarihlenen Eski Türkçe külliyatın tamamında yalnızca bir kez rastladığı ve XIII. yy. sonrasında ya da Türk dil ailesinin çağdaş sözlüklerinde karşılığını bulamadığ1 sözcükler için kullandığı anlaşılmaktadır. Örneğin, Eski Türkçe döneminde sadece DLT'de geçen üplä- 'çalmak' sözcüğü Tuvacada üptä- 'çalmak' şeklinde varlığını sürdürdüğü için Clauson (1972, s. 11a) tarafından hapax olarak tanımlanmazken, Eski Türkçe döneminde yine sadece DLT'de geçen üplät- 'çaldırmak' (s. 11a) ve üpläş- 'birbirinin malını çalmak' (s. 11b) fiilleri XIII. yy. sonrası metinlerle ya da çağdaş Türk dilleriyle tanıklanamadığı için hapax kaydıyla verilmiştir. Benzer şekilde, ED'deki açış- $I$ 'açmasına yardım etmek; açmakta yarış etmek' (s. 31b) fiili Eski Türkçede sadece DLT'de yer aldığı hâlde bu fiil Hakasça ve güney doğu grubunda varlığını sürdürdüğü için hapax olarak nitelendirilmezken Eski dönem metinlerinde sadece DLT'de geçen açsa- 'açmak istemek' ve içsä- 'içmek istemek' (s. 31b) fiilleri Karahanlı Türkçesi sonrasında tespit edilemediği için bunlara kaydı düşülmüştür.

Clauson (1972), ED’ye hazırlık aşamasında sadece bir örneğine rastladığı sözcükler için hapax kaydını düşerken bunların ileride hapax özelliğini yitirebileceğini de yazmıştır (bk. s. vii). Nitekim Türkolojide araştırmacıların hapaxlara dolaylı olarak değindiği (örn. Erdal 1991; Ölmez 2000) ya da Eski Türkçe hapaxları tarihî ve çağdaş Türk dilleriyle doğrudan karşılaştırdığı pek çok çalışma yapılmış (Ata 2010; Ayazlı 201; Doğan 2019; Ölmez 2008, 2011; Tezcan 2008; Uçar 2012; Y1ldız 2011, 2014; Küçük, Demirci 2016) ve kimi sözcükler Clauson'un isabetle öngördüğü gibi hapax olmaktan çıkmıştır.

1 Clauson'un (1972), Etimolojik Sözlük'ün Önsöz'ünde Türkçenin XIII. yüzyıldan önceki söz varlığının şaşılacak bir bölümünün hapax olduğunu belirttiğini ancak belirli bir sayı vermediğini alıntılayan Yıldız'ın sayımına göre bu sözlükte hapax niteliğindeki sözcük sayısı 2225 adettir. Sözlükte yaklaşık 9600 madde başı olduğunu kaydeden Yıldız (2011), Clauson'un çalışmasına dahil ettiği verilerin neredeyse \% 25'inin hapax olduğu sonucuna ulaşmıştır (bk. s. 22). 
Türk dil ailesinin en ayrıksı dillerinden biri, Kıpçak grubuna dahil olan, anlambilimi, söz varlığı ve söz yapımı bakımından hem kendi grubuna hem de diğer Türk dillerine nazaran kimi eskicil ögeler barındıran Başkurtçadır. Günümüzde söz varlığı açısından bir değerlendirmeye gidildiğinde, çağdaş Türk dillerinde kullanımdan düşmüş bulunan çok sayıda Eski Türkçe sözcüğün eskicil anlamlarını koruyarak Başkurtçada varlığını sürdürdüğü görülmektedir. Ancak Clauson (1972), Kıpçak grubun geri kalanından çok fazla farklılaştığg için Başkurtçayı (bk. s. xxviii) sözlüğünde hiç değerlendirmeye almadığını belirtmektedir ${ }^{2}$. Bu durumda Eski Türkçe hapaxlar ile Başkurtça arasında yapılacak bir karşılaştırmanın Etimolojik Sözlük’teki kimi hapax bilgilerini değiştirecek veriler sunması beklenebilir.

Bu makale Eski Türkçe metinlerde hapax olarak geçen Türkçe söz varlığ ile Başkurtçanın söz varlığını karşılaştırmak ve bu sözcüklerin Başkurtçada varlıklarını sürdürüp sürdürmediklerini belirlemek amacıyla hazırlanmıştır. Eski Türkçe metinlerdeki hapaxları belirlemek için Clauson'un Etimolojik Sözlük'ündeki verilerden yararlanılmıştır. Bu karşılaştırma için Başkurtçanın seçilmesindeki temel ölçüt, Başkurtçanın söz varlığının eski ve çağdaş Türk dilleri arasındaki leksik karşılaştırmalar açısından çalışılmamış bir alan olmasıdır. Makalenin hazırlık aşamasında Etimolojik Sözlük'teki hapaxlar Başkurtçada aranırken Axmerov vd. (1958) tarafından hazırlanan Başkirsko-Russkiy slovar' ve Özşahin (2017) tarafından hazırlanan Başkurt Türkçesi Sözlüğü kullanılmıştır ${ }^{3}$ Bu iki kaynağın taranması sonucunda Etimolojik Sözlük'te hapax olarak verilen 32 sözcügün Başkurtçada varlığını sürdürdüğü ortaya çıkmış ve makalede bu sözcükler üzerinde durulmuştur.

Çalışma üç bölüm olarak tasarlanmıştır: Giriş bölümünde hapax terimi, Başkurtça ve hapaxlar üzerine yapılan çalışmalarla ilgili kısaca bilgi verilmektedir. İkinci bölümde Eski Türkçe hapaxlar ile Başkurtça arasında yapılan karşılaştırma sonucunda hapax niteliğini yitiren 32 sözcük ele alınmaktır. Üçüncü bölüm ise elde edilen bulguların özetlendiği Sonuç bölümüdür.

\section{Başkurtçayla Tanıklanabilen Hapaxlar:}

1. ET bagırlan- '(kan) pıhtılaşmak; ekşimiş yoğurt kesilmek' (Clauson, 1972, s. 320a): Baş. bavırlan- 'koyu ve katı hale gelmek; pıhtılaşmak (kan ve yoğurt gibi şeyler için)' (Özşahin, 2017, s. 67).

Clauson'un etimolojik sözlüğündeki hapaxlardan olup Başkurtçayla tanıklanabilen ilk veri ET bagırlan- > Baş. bavırlan- denkliğidir. Türk dilinin tarihi dönem metinlerinde ilk ve son olarak DLT'de geçen, günümüz Türk dillerinde de karşılığı bulunmayan bu sözcük, Başkurtçada iki ünlü arasında - $g$ - > - v- değişimi dışında başka bir fonolojik değişim göstermemiştir. Semantik olarak bakıldığında, sözcüğün DLT'de kayıtlı anlamını bire bir koruduğu görülmektedir. Bu

2 Clauson'un ED’de neredeyse hiç yer vermediği bir diğer dil de Yakutçadır. Sözlükte XIII. yy. öncesi dil malzemesi ile karşılaştırılan Yakutça sözcük sayısı 10 kadardır (Yıldız, 2011, s. 22). Clauson Türk dillerinin geri kalanından çok erken bir dönemde ayrılıp izole olduğu ve fazlasıyla kendisine has özellikler kazandığı için Yakutçayı değerlendirmeye dahil etmediğini belirtmiştir bkz. s. xxvii.

3 Başkurt dilinin diğer sözlükleri hakkında detaylı bilgi için bk. Özşahin, 2020. 
veri Başkurtçanın en eski sözlüğü olan Axmerov vd. (1958)'de madde başı olarak yer almazken Özşahin (2017) aracılığıyla tanıklanabilmektedir.

2. ET bıçış- 'biçmekte yarışmak; birlikte biçmek' (Clauson, 1972, s. 296a): Baş. bısış̧'birlikte ya da karşılıklı testere ile kesmek, testere ile biçmek' (Özşahin, 2017, s. 86).

Clauson'un Etimolojik Sözlük'ü yayımladığı dönemde ilk olarak DLT aracılığıyla tanıklanabilen bir diğer veri de ET bıçış- fiilidir. Clauson bu sözcüğün hapax olup olmama durumunu soru işaretiyle belirtmiştir. Günümüzde ET bıçış- fiilinin DLT'den önce, Eski Uygurca metinlerde de geçtiği ortaya çıkmıştır (Wilkens, 2021, s. 167)

Başkurtçada en tipik ses kurallarından biri olan /ç/ > /s/ gelişimi dışında fonolojik bir değişim göstermeyen bısış- fiili, semantik olarak DLT'deki anlamdan uzaklaşmamıştır. Başkurtça bısışfiili de tıpkı bavırlan- gibi Axmerov vd. (1958)'de madde başı olarak yer almazken Özşahin (2017) aracılığıyla tanıklanabilmektedir.

3. ET bürçäklän- '(at) perçemlenmek' (Clauson, 1972, s. 358a): Baş. börsöklen'kabarcıklanmak, tanecik tanecik olmak' (Özşahin, 2017, s. 106).

Türk dilinin tarihi metinlerinde ilk ve son olarak DLT'de geçen bürçäklän- fiilinin kökü olan bürçäk 'kıvırcık, lüle; perçem' (Clauson, 1972, s. 357) ismi, Clauson'a göre bür- 'burkmak, kıvırmak' (1972, s. 355a) fiilinden türemiştir. Clauson bu düşüncesinden ötürü kuzey-doğu Türk dillerindeki pürçük bürçük bürşik 'tomurcuk, gonca, sürgün, filiz' sözcüklerini etimolojik bakımdan ayrı veriler olarak değerlendirmiş ve bunları Eski Uygurcadaki varlığı kuşkulu olan ancak pek çok Türk dilinde varlığını sürdüren bür 'tomurcuk, gonca, sürgün, filiz' (Clauson, 1972, 354a) isminden getirmiştir. KD dillerindeki verilere benzer anlamlı Başkurtça börsök ' 1 . zerre, parça, kırıntı, çok küçük parça; 2. çok küçük kabarcık’ (Özşahin, 2017, s. 106) sözcüğü de buraya dahil edilebilir. Clauson bürçäk maddesi içinde değindiği, güney-doğu grubuna ait burcek bürcek ve Kırgızca bürçök 'köşe, açı' sözcüklerini ise Doerfer II 731'e dayanarak Arapça burc sözcüğüyle ilişkili ayrı veriler olarak ele almıştır.

Clauson'un bürçäk sözcügünü bür- fiiline bağlayan etimolojisine katılmak zordur. Çünkü ilk olarak DLT'de geçen bürçäk sözcüğünün 'perçem, kâkül' anlamıyla kuzey-doğu Türk dillerindeki pürçük bürçük bürşik biçimlerinin ‘tomurcuk, gonca, sürgün, filiz' anlamları, bir gövdeden çıkan daha küçük uzantıları ya da küçük kabarcıkları ifade ettiği için birbiriyle ilintilidir. Buna bağlı olarak DLT'deki bürçäklän- ve Başkurtçadaki börsöklen- fiillerinin bağlantılı olduğu düşünülebilir.

Yukarıda değinilen bavırlan- ve bısış- verileri gibi börsöklen- fiili de Axmerov vd. (1958)'de yer almayıp Özşahin'in sözlüğü aracılığıyla tespit edilebilmektedir. DLT'ye ait dönüşlü bürçäklän- gövdesinin kendisinden türediği etken çatılı *bürçäklä- fiiline tarihî dönem metinlerinde geçmez. Ancak *bürçäklä- fiilinin de Başkurtçada börsökle- 'saçmak, serpmek' (Axmerov vd., 1958, s. 113), börsökle- 'uçlarını temizlemek, çözülmüş, sökülmüş 
bir şeyin saçaklarını, iplerini temizlemek' (Özşahin, 2017, s. 106) olarak varlığını sürdürdüğü görülmektedir.

4. ET bürgälän- 'öfkeden pire gibi zıplamak' (Clauson, 1972, s. 364b): Baş. birělen'dağıtıp kızıp gitmek; kudurmak; deli gibi davranmak' (Özşahin, 2017, s. 92).

Buraya kadar üzerinde durduğumuz diğer sözcükler gibi bürgälän- fiili de Eski Türkçede ilk olarak DLT' de geçen verilerden biridir. ET bürgä sözcügünden $+l A$ - ve - $n$ - ekleriyle türeyen ve DLT'ye mecaz anlamıyla giren bu dönüşlü fiilin birincil anlamı, Türkçe pirelen- fiilindeki gibi 'üzerinde pire bulunmak, pirelenmek' olmalıdır. Başkurtça biçimin DLT’de verilen anlamı günümüzde de korumuş olması ise dikkate değer bir noktadır.

Başkurtça bavırlan-, bısış- ve börsöklen- fiilleri gibi birělen- fiili de Axmerov vd. (1958)'de madde başı olarak yer almayıp yalnızca Özşahin (2017) aracılığıyla tanıklanabilmektedir.

5. ET ärsäklän- 'bir erkeğe ilgi duymak' (Nadelyaev vd., 1969, s. 181), *ärsäglän'şehvetten ötürü erkek aramak' (Clauson, 1972, s. 239a): Baş. irheklen- 'cilvelenmek, cilveli olmak' (Özşahin, 2017, s. 257).

Clauson'un sözlügüünde hapax olarak kaydedilen bu sözcük yukarıda görüldügü üzere Nadelyaev vd. (1969) tarafindan ärsäklän-, Clauson (1972) tarafindan ärsäglän- olarak okunmuştur. Clauson fiilin türediği isim gövdesini de ärsäg (1972, s. 237b) okuyuşuyla madde başı yapmıştır. Burada Clauson'un *ärsäg ve *ärsäglän- okuyuşları hatalıdır. Çünkü kendisinin de *ärsäg maddesinde belirttiği üzere, sözcük neredeyse bütün dil gruplarında ärsäk olarak varlığını sürdürmektedir. ET ärsäklän- fiilinin türediği bu isim gövdesi Başkurtçada da irhek ‘erkek sever; cilveli, erkeklerin başını döndürmeyi seven’ (Özşahin, 2017, s. 257) biçimindedir.

Buraya kadar yer verdiğimiz dört fiil gibi ET ärsäklän- fiili de Axmerov vd. (1958)'de yer almayıp Özşahin (2017) aracılığıyla tanıklanabilmektedir. Sözcüğün Başkurtçada DLT'de verilen eskicil anlamını koruduğu görülmektedir.

6. ET ätlä- 'şişmanlatmak, semirtmek (?)' (Clauson, 1972, s. 57b): Baş. itle- '1. deriyi parçalamadan birleştirip dikmek; 2 . deri ayakkabı dikildiğinde birleşim yerine ince bir deri parçası sıkıştırarak dikmek' (Özşahin, 2017, s. 265).

Clauson'un anlamını soru işaretiyle verdiği, ET ät 'et' isminden $+l A$ - ekiyle türemiş olan bu hapax da ilk olarak DLT' de geçen ve Başkurtçayla tanıklanabilen bir başka veridir. ET ätläsözcüğünün Başkurtça dışında Yakutça, Dolganca, Kırgızca ve Tuvacada varlığını sürdürdüğü önceki araştırmalar aracılığıyla ortaya çıkarılmıştır (bkz. Yıldız, 2011, s. 28). ET ätlä- fiili de Axmerov vd. (1958)'de yer almayıp Özşahin (2017) aracılığıyla tanıklanabilmektedir.

7. ET Itla- 'bir kimseyi köpek yerine koymak' (Clauson, 1972, s. 57b): Baş. ětlě- 'azap çektirmek, sıkıntı vermek, eziyet çektirmek, eza göstermek’ (Axmerov vd., 1958, s. 689; Özşahin, 2017, s. 159). 
DLT'de geçen bu sözcük Clauson tarafından soru işaretiyle hapax olarak verilmiştir. ET ıtla- fiili, yayımlandığı yıl itibarıyla Clauson'un yararlanabileceği Axmerov vd.'de geçtiği hâlde Clauson Başkurtçayı değerlendirmesine dahil etmediği için bu veri Etimolojik Sözlük'e hapax olarak girmiştir. Üstelik Yıldız’ın (bk. 2014, s. 40) bahsettiği üzere, bu ET sözcüğün Clauson'un çok az sayıda karşılaştırma yaptığı Yakutçayla tanıklanması da mümkündür.

Eski Türkçe döneminin bu nadir fiili, Yakutçada ıttaa- 'bir kimseyi köpek olarak nitelemek; köpek diyerek sövmek' (Pekarskiy, 1928, s. 3844) olarak geçmekte ve bu anlam Eski Türkçe ile birebir örtüşmektedir. Başkurtçada ise anlam genişlemesi meydana gelmiştir.

8. ET isiglä- 'yaz sıcağında yürümek' (Clauson, 1972, s. 247a): Baş. éšěle- '2. sicaklamak, havasız kalmak' (Axmerov vd., 1958, s. 688), ěsěle- '1sıtmak, kaynatmak, sıcak hale getirtmek' (Özşahin, 2017, s. 157).

Türk dili alanında ilk olarak DLT'de geçen ve daha önce Yakutça ve Kırgızcada varlığını sürdürdüğü ortaya çıktığı için hapax niteliğini yitiren bu sözcük (bkz. Yıldız, 2011, s. 34) bu iki dil dışında Başkurtçayla da tanıklanabilmektedir. Başkurtça sözcüğün Axmerov vd.'de verilen 'sıcaklamak' anlamı DLT’deki daha eskicil anlama yakınken günümüz Başkurtçasında anlam değişimi meydana gelmiştir. ET anlam dönüşlüyken, Başkurtça anlam ettirgendir.

9. ET kadışla- '(gönlenmiş deriyi) kayış şeklinde kesmek' (Clauson, 1972, s. 607b): Baş. kayışla- 'kayış, kemer, vs. ile vurmak' (Özşahin, 2017, s. 341).

Başkurtçada Kıpçak dil grubu için tipik olan $-d->-y$-gelişimi dişında fonolojik değişim göstermeyen kayışla- sözcüğü, Axmerov vd.'nin sözlüğünde yer almaz ${ }^{4}$. Eski Türkçe döneminde yine ilk olarak DLT'de kaydedilen kadışla- fiili, +lA- ekinin DLT'de yaygın görülen 'bir şeyle vurmak’ anlamıyla Başkurtçada varlığını sürdürmektedir.

10. ET ka:rlan- 'karla kaplanmak' (Clauson, 1972, s. 659a): Baş. karlan- '1. karla kaplanmak, karlanmak; 2. kar haline dönüşmek' (Axmerov vd., 1958, s. 509), karlan- 'kara gömülmek, kara batmak' (Özşahin, 2017, s. 332).

Buraya kadar ele alınan diğer sözcüklerde olduğu gibi Eski Türkçe döneminde ilk olarak DLT aracılığıyla tanıklanan karlan- sözcüğü, Clauson'un hapax olarak nitelendirdiği verilerden biridir. Bu fiilin Yakutça, Türkiye Türkçesi ve Hakasçada varlığını sürdürmekte olduğu ve hapax niteliği taşımadığı geçmişteki çalışmalarla ortaya konmuştur (bk. Yıldız, 2014, s. 41). Bu ET fiilin Başkurtça karşılığı hem Axmerov vd.'nin sözlüğünde yer alan hem de günümüz Başkurtçasında kullanılan sözcüklerden biridir.

11. ET käçtür- '(sudan) geçirmek' (Clauson, 1972, s. 696a): Baş. kistěr- '1. geçirmek, vazgeçirmek; 2. aşırmak’ (Özşahin, 2017, s. 291).

Eski Türkçede käç- fiil kökünün ettirgen biçimleri olarak käçür- (Clauson, 1972: 698a), käçit- I (Clauson, 1972: 695b) ve keçtür- sözcükleri karşımıza çıkar. Bunlardan ilki Şine Usu

4 Axmerov vd., yalnızca fiilin edilgen çatılı kayışlan- (1958, s. 315) biçimine yer verir. 
yazıtından başlayarak tüm tarihî dönemlerde görüldüğü gibi, günümüz Türk dillerinde de hala kullanılmakta olan biçimdir (Clauson, 1972: 698a). Käçit- ve käçtür- gövdeleri ise yalnızca Kaşgarlı'nın kaydettiği sözcükler olup Clauson tarafından hapax olarak nitelendirilmiştir.

ET käçtür- sözcügünün Clauson'un nadiren başvurduğu Pekarskiy sözlüğü aracılığıyla Yakutçada; sıklıkla atıfta bulunduğu Yudahin sözlüğü aracılığıyla ise Kırgızcada tanıklanabileceği, dolayısıyla fiilin Etimolojik Sözlük'te hapax olarak nitelendirilmemesi gerektiği Yıldız (2014, s. 41) tarafindan ortaya konmuştur. Başkurtça açısından bakıldığında, Clauson'un basım yılı itibarıyla atıfta bulunmasının mümkün olduğu Axmerov vd.'de (1958) fiilin Başkurtça denginin zaten yer almadığı görülür. Ancak günümüz Başkurtçasındaki kistěr- biçimi hem Eski Türkçedeki birincil 'aşırmak' anlamını korumakta hem de aynı fiil kökünden diğer bir ettirgenlik ekiyle türeyen ET käçür- fiilinin günümüz Türk dillerinde yaygın olarak kullanılan 'vazgeçirmek' anlamını da içermektedir. Ayrıca, Wilkens' in Eski Uygurca sözlüğünün yayımlanmasıyla ET käçtür- fiilinin Eski Uygurcada da var olduğu ortaya çıımıştır (2021, s. 352).

12. ET kıdıgla- '(şapkaya) siper dikmek' (Clauson, 1972, s. 600b): Baş. kıyıvla- 'şeritlemek, çizgilemek, zıhlamak, zıh çekmek’ (Özşahin, 2017, s. 363).

ET kıd-fiilinden -(I) $g$ ve $+l A$ - ekiyle türeyen, DLT'ye ait bu fiilin isim gövdesi olan kıdıg sözcüğü hem tarihi hem çağdaş Türk dillerinde çeşitli fonolojik değişimlerle yaygın olarak kullanılmaktadır (bk. Clauson, 1972, s. 588a). ET kıdıgla- sözcüğü ise Etimolojik Sözlük'te hapax kaydıyla verildiği hâlde aslında Clauson'un atıfta bulunduğu Yakutça, Şorca ve Türkçe kaynaklarda geçtiği için (bk. Yıldız, 2014, s. 42) hapax olarak tanımlanmaması gereken verilerden biridir. ET fiilin dengi Axmerov vd.' de (1958) yer almazken ${ }^{5}$ fiil günümüz Başkurtçasında klyıvla- olarak varlığını sürdürmektedir.

13. ET küglän- I 'şark1 söylemek' (Clauson, 1972, s. 711b): Baş. köylen- '1. köyle- 1', $3^{7}, 4^{8}$ 'ün edilgen biçimi; 2. (insan için) ikna olmak, boyun eğmek; (iş için) iyi gitmek, yoluna girmek' (Axmerov vd., 1958, s. 276), köylen- '1. melodili olmak; ahenkli olmak; 2. düzgün olmak, düzenli olmak; 3. şiir söylenmek, belli bir ezgide söylenmek, terennüm edilmek’ (Özşahin, 2017, s. 302).

ET küg I 'şark1, nağme' (Clauson, 1972, s. 709b) adından +lA- ve -(I)n- ekleriyle türeyen ve ilk olarak DLT'de kaydedilen bu dönüşlü fiil gövdesi, Başkurtçada tek heceli sözcüklerin sonunda $-g>-y$ değişimiyle hem Axmerov'un hem Özşahin'in sözlüğünde geçen verilerden biridir. Clauson'daki bilgilere göre, ET küglän- fiilinin türediği küg adı pek çok kuzey doğu dilinde, küglä- (bk. s. 711a) fiiliyse yalnızca Kırgızcada varlığını sürdürmektedir. Clauson Axmerov vd.'deki köyle- fiilini görmediği için bu açıklamaya yer vermiştir. Kısacası ET küglä- I fiili Kırgızca ile birlikte Başkurtçada, ET için hapax kaydıyla verilen küglän- fiili ise sadece Başkurtçada fonolojik değişimle varlığını sürdürmektedir.

5 Bu sözlükte sadece fiilin edilgen klyılan- (s. 356) gövdesi bulunur.

6 '(müzik aleti için) akort etmek'

7 '(bir şeyi) ayarlamak, düzenlemek'

8 '(usturayı) bilemek' 
14. ET küzä:- 'güzü geçirmek' (Clauson, 1972, s. 757b): Baş. köźe- 'ilkbaharda bir yaşındaki hayvanların yele ve kuyruklarını kesmek' (Axmerov vd., 1958, s. 275); köźe- 'tay ya da sıpaların baharda kuyruğunu kısaltmak, kuyruk tüylerini kesmek; 2. uçlarını kesmek, traş etmek' (Özşahin, 2017, s. 303).

Eski Türkçe döneminde yine ilk olarak DLT'de geçen ve Clauson tarafından hapax notu düşülen bu sözcüğün Eski Uygurca, Yakutça ve Tuvacada varlığını sürdürdüğü ve aslında Etimolojik Sözlük'teki kayıtlara hapax olarak girmemesi gerektiği daha önce Yıldız tarafından dile getirilmiştir (2014, s. 42). Şimdi ET küzä- fiilini koruyan diller arasına Başkurtça da eklenebilir.

Eski Türkçe küzä- fiilinin birincil 'güzü geçirmek' anlamı günümüzde Yakutça ve Tuvacada korunmaktadır (bk. Yıldız, 2014, s. 44). Tuvaca fiilin 'güzü geçirmek' ile birlikte 'güz boyunca bir durumda olmak (örn. güz boyunca hasta olmak); güz boyunca bir şeyle meşgul olmak’ (Tenişev, 1968, s. 269) anlamları da vardır. Sözcük Başkurtçada önce Tuvacadaki gibi 'güz boyunca bir şeyle meşgul olmak' anlamını, daha sonra tekrar genişlemeyle 'yılın bir mevsiminde bir şeyle meşgul olmak’ anlamını kazanmış olmalıdır. Belli bir mevsimde yapılan bu şey Başkurtlar için spesifik olarak 'kuyruk kırkmak’tır.

15. ET örüm ‘örülmüş ya da dokunmuş şey’ (Clauson, 1972, s. 231b): Baş. ürěm 'saç örgüsü’ (Axmerov vd., 1958, s. 588), ürěm 'örülmüşs şey, örgü’ (Özşahin, 2017, s. 261).

Clauson'un Etimolojik Sözlük'ü yayımladığı dönemde yine ilk kez Karahanlı Türkçesinde fakat bu kez Kutadgu Bilig aracılığıyla tanıklanabilen bu veri, Clauson tarafından soru işaretiyle hapax olarak kaydedilmiştir. Ancak günümüzde sözcügün Eski Uygurcada da var olduğu ortaya çıkmıştır (bk. Wilkens, 2021, s. 542). Dolayısıyla bu sözcük hem Eski Uygurcada hem Başkurtçada varlığını sürdüren bir veri olduğu için hapax niteliğini yitirmektedir.

16. ET talagu 'etkili zehir; dizanteri' (Clauson, 1972, s. 497b): Baş. talav 'sığır, koyun gibi hayvanlardaki ağrılı şişik’ (Özşahin, 2017, s. 573).

ET tala- 'tahrip etmek, yağmalamak' (Clauson, 1972, s. 492a) fiilinden - $G U$ ekiyle türeyen ve ilk olarak DLT'de geçen bu sözcük, Başkurtçada sözcük sonunda /A $\dot{g} U$ A $\dot{g} I />$ /Av/ değişimiyle ${ }^{9}$, yine bir tür hastalık adı olarak varlığını sürdürmekte ve hapax niteliğini yitirmektedir. Axmerov'da (1958, s. 502) verilen talav sözcüğü ise '2. 1. yağma, talan; 2. zorlama, cebir; 3. dalama, ısırma' anlamlarıyla madde başı yapılmıştır. Bu sözcük semantik olarak *tala-g gövdesine gittiği için DLT'de geçen ad gövdesiyle bağlantılı değildir.

17. ET tarmaklan- 'boylar bozkırda pençe gibi her yöne doğru yerleşmek; yavrunun pençeleri çıkmak; su kanallar açmak' (Clauson, 1972, s. 550b): Baş. tarmaklan- '1. (saç,

9 Bu fonolojik değişim için ayrıca ET küdägü 'damat, güveyi' (Clauson, 1972, s. > Baş. kěyěv 'ay.' (Özşahin, 2017, s. 283), ET yagl 'düşman' (Clauson, 1972, s. 898a) > Baş. yav 'savaş, muharebe, meydan muharebesi, cenk, kavga” (Axmerov vd., 1958, s. 727) vb. 
sakal) uzatmak, dal dudak salmak, ayrı ayrı yönlere ayrılmak, kollara ayrılmak, sürgün vermek' (Axmerov vd., 1958, s. 509), tarmaklan- 'dallanmak, budaklanmak, dallara ayrilmak' (Özşahin, 2017, s. 582).

ET tarmak 'pençe, dal budak' (Clauson, 1972, s. 549b) adından $+l A$ - ve -(I)n- ekleriyle türeyen ve DLT'ye ait tarmaklan- sözcügü daha önce Yakutça, Kırgızca ve Yeni Uygurcayla tanıklanarak (bk. Yıldız, 2014, s. 46) hapax niteliğini yitirmiş bir veridir. Bu üç Türk dilinin yanına hiçbir fonolojik ve semantik değişim geçirmeyen Başkurtça biçim de eklenmelidir.

18. ET tartışlıg ‘(erkeği) sürükleyen’ (Clauson, 1972, s. 537b): Baş. tartışlı 'çekişmeli, mücadeleli, kavgalı’ (Özşahin, 2017, s. 583).

Buraya kadar değindiğimiz tüm verilerden farklı olarak ilk kez bir Manihaist Uygur metninde geçen bu sözcük *tartış adından türemiş bir sıfat olarak kullanılmıştır. ET'de görülmediği için Clauson'un *tartış şeklinde verdiği bu ad gövdesi, Tarama sözlüğüne dartış 'niza, çekiş' şekliyle girmiştir. Clauson’un hapax kaydıyla verdiği ET tartışlıg sözcüğüne denk Başkurtça tartışlı biçimi Axmerov vd.' de yer almazken Özşahin'in sözlüğü aracılığıyla günümüz Başkurtçasında tanıklanabilmekte ve hapax niteliğini yitirmektedir.

19. ET tayış- 'kaymakta yarışmak' (Clauson, 1972, s. 570a): Baş. tayış- '1. ayrılmak, sapmak; 2. meyletmek’ (Özşahin, 2017, s. 589).

Eski Türkçe döneminde yine ilk olarak DLT'de geçen ve Clauson tarafindan hapax notu düşülen bu sözcük, DLT'de işteş fiil çatısının sıkça kullanılan 'fiil kök ya da gövdesinin gösterdiği harekette yarışmak' işleviyle kayıtlıdır. ET tayış- fiilinin türediği tay- 'kaymak, meyletmek' (Clauson, 1972, s. 567a) kökü pek çok çağdaş Türk dilinde varlığını sürdürürken tayış- gövdesi yalnızca Başkurtçayla tanıklanabilmektedir. Bu fiil gövdesi Axmerov vd.'de kayıtlı değildir.

20. ET tämürlük 'demir işliği' (Clauson, 1972, s. 509b): Baş. timěrlěk 'demirhane' (Axmerov vd., 1958, s. 526), timěrlěk 'demir işlenen yer, demir dövülen yer’ (Özşahin, 2017, s. 616).

Yine ilk kez DLT'de geçen verilerden biri olan tämürlük sözcüğü, Başkurtçada fonolojik olarak farklılaşmış ancak hiçbir semantik değişime uğramamış verilerden biridir. Bu sözcük de Clauson'un Başkurtçayı değerlendirme dışı bırakmaması durumunda Etimolojik Sözlük'te hapax kaydıyla verilmeyecek bir sözcüktür. Çünkü yukarıda da belirtildiği üzere, basım yılı itibarıyla Clauson'un Axmerov vd. (1958)'den yararlanması mümkündür.

21. ET tişät- '(orak, değirmen taşı için) dişlerini biletmek' (Clauson, 1972, s. 562a): Baş. těşet- 'těşe- I' in ettirgen biçimi' (Axmerov vd., 1958, s. 523), těşet- 'aletlerin dişlerini keskinletmek, aletlere diş açtırmak’ (Özşahin, 2017, s. 603).

Eski Türkçede ilk olarak DLT'de geçen ve Clauson tarafindan soru işaretiyle hapax olarak tanımlanan tişät- fiilinin Yakutça, Türkmence ve Özbekçede varlığını sürdürdüğü ve aslında hapax niteliği taşımadığı daha önce Yıldız (2014, s. 47) tarafından ortaya çıkarılmıştır. 
Başkurtça těşet- fiili Axmerov vd.'de yalnızca 'těşe- I' in ettirgen biçimi' açıklamasıyla kayıtlıdır. ${ }^{10}$ Buna göre Başkurtça těşet- fiili hem 20. yüzyılın ilk yarısında hem de günümüz Başkurtçasında kullanılan ve yukarıda anılan diğer üç dille birlikte

ET tişät- maddesi dahilinde örneklendirilmesi mümkün olan bir veridir.

22. ET tüplän- '(ağaç) köklenmek' (Clauson, 1972, s. 440b): Baş. töplen- I 'töple- I, II, III' ün edilgen biçimi' (Axmerov vd., 1958, s. 540), töplen- '1. bir yere yerleşmek; 2. toprağa kök saldırmak' (Özşahin, 2017, s. 632)

Eski Türkçe tüp 'ağaç ya da bitki kökü; temel, taban; dip; ata, köken' (Clauson, 1972, s. 434b) adından $+l A$ - ve -(I)n- ekleriyle türeyen ve ilk olarak DLT'de kaydedilen bu dönüşlü fiil gövdesi, hem Axmerov’un hem Özşahin'in sözlüğünde töplen- şeklinde kayıtlıdır. Üstelik sözcük Türkiye Türkçesi ağızlarında da diplen- 'yerleşmek, durumunu düzeltmek' (Derleme S., 1969, c. 4) anlamıyla varlığını sürdürmektedir.

23. ET tüplät- 'derinlemesine araştırtmak' (Clauson, 1972, s. 440b): Baş. töplet- 'töpleI, II, III'ün ettirgen biçimi' (Axmerov vd., 1958, s. 540), töplet- '1. kova, kap ya da sepet gibi şeylere dip koydurmak; 2. ayakkabıya taban çaktırmak, taban taktırmak’ (Özşahin, 2017, s. 632).

Clauson Etimolojik Sözlük'te Eski Türkçe tüp adından +lA- ekiyle türeyen tüplä- fiilinin yalnızca Baraba Tatarcasında 'temel atmak; dibine ulaşmak; derinlemesine araştırmak' (1972, s. 440b) anlamlarıyla varlığını sürdürdüğünü yazmış; DLT’deki ettirgen tüplät- gövdesi içinse hapax kaydını düşmüştür. Ancak DLT'ye ait bu fiil, hem 20. yüzyılın ilk yarısında hem de günümüz Başkurtçasında töplet- biçimiyle kullanıldığı için hapax niteliği taşımamaktadır. DLT'de 'derinlemesine araştırtmak' anlamıyla geçen tüplät- fiili, Baraba Tatarcasındaki tüple- gövdesiyle semantik yakınlık göstermektedir. Başkurtça sözcük ise tüp adının somut anlamından türetilmiştir.

24. ET tüşlük 'dinlenme vakti, mola' (Clauson, 1972, s. 564a): Baş. töşlök' 'güney' (Axmerov vd., 1958, s. 543), töşlök ‘1. güneşin en tepede olduğu nokta; 2. güney; 3. öğle vakti; 4. öğle yemeği’ (Özşahin, 2017, s. 635).

Clauson ilk olarak DLT'de geçen tüşlük sözcügünün ET tüş III 'mola' (1972, s. 559a) isminden türediğini belirtir ve sözcügü hapax olarak kaydeder. Burada görüldüğü üzere ET tüşlük sözcüğü hem 20. yüzyılın ilk yarısında hem de günümüz Başkurtçasında töşlök olarak varlığını sürdürmüştür. Clauson tüş III maddesinde, dinlenme vakitlerinin öğlene denk gelmesi nedeniyle bu sözcügün 'gün ortası, öğle vakti' anlamlarına da geldiğini ve bu anlamda pek çok Türk dilinde yaşadığını belirtmiştir. Başkurtça töşlök sözcüğü temel ‘mola' anlamını yitirmiş olup ikincil ‘öğle vakti’ ve 'güney’ anlamlarıyla kullanılmaktadır.

10 Sözlükteki těşe- I fiili ‘(orak, değirmen taşı üzerinde) diş açmak, çentik açmak’ anlamlarındadır (s. 523). 
25. ET üklüş- 'birbiri üzerine yığılmak' (Clauson, 1972, s. 107b): Baş. öyölöş- 'toplaşmak, yığılmak' (Axmerov vd., 1958, s. 424), öyölöş- 'karş1lıklı ya da birlikte yığılmak, toplanmak, birikmek; birbiri ardına gelmek, üst üste gelmek’ (Özşahin, 2017, s. 469).

Eski Türkçe $\ddot{u} k$ - fiilinden edilgenlik ve işteşlik ekiyle türeyip ilk olarak DLT'de geçen bu sözcük, Başkurtçada iki ünlü arası -k->*-g->-y-gelişimiyle varlığını sürdürdüğü için hapax niteliğini yitirmektedir. Sözcüğün Başkurtçada semantik değişime uğramadığı görülmektedir.

26. ET yazlat- 'yaylada baharı geçirtmek' (Clauson, 1972, s. 987b): Baş. yaźlat- 'baharı geçirtmek’ (Özşahin, 2017, s. 705).

Eski Türkçede ilk olarak DLT'de geçen yazlat- sözcüğünün Başkurtçada korunduğu hâliyle /z/ > /ź/ değişimi dışında başka bir fonolojik gelişim göstermemiştir. Axmerov vd.'de ettirgen yaźlat- gövdesine değil, yalnızca yaźla- 'baharı geçirmek' (1958, s. 714) fiiline yer verilmektedir. Başkurtçada Özşahin'in sözlüğü aracılığıyla tanıklanabilen yaźlat- sözcügünün semantik değişim geçirmediği görülmektedir.

27. ET yemsin- 'yiyormuş gibi yapmak' (Clauson, 1972, s. 938a): Baş. yěmhěn- 'yem aramak’ (Özşahin, 2017, s. 713).

DLT'de oldukça fazla sayıda türetimde karşımıza çıkan $+s I n$ - isimden fiil yapma eki Eski Türkçede nadiren kullanılan $+s I$ - ekiyle -(I)n-dönüşlülük ekinin birleşmesiyle oluşan ve genelde benzerlik fiilleri türeten bir ektir (Clauson, 1972, s. xlvi). Eski Türkçe $+s I n$ - eki Başkurtçada ek ve sözcük başlarında kurallı/s/ > /h/ değişimiyle günümüzde de pek çok türetimde görülen işlek bir ektir. Axmerov vd.'de yer almayan Başkurtça yěmhěn- fiili Eski Türkçedeki benzerlik anlamından uzaklaşmış olsa da Özşahin'in sözlüğü aracılığıyla tanıklanabilmektedir. Bu durumda ET yemsin- fiili hapax niteliğini yitirmektedir.

28. ET yersin- 'bir yeri benimsemek' (Clauson, 1972, s. 971b): Baş. yěrhěn- '(birine, bir şeye) alışmak; benimsemek' (Axmerov vd., 1958, s. 430), yěrhěn- 'bir yeri, toprağı benimsemek' (Özşahin, 2017, s. 719).

Yukarıdaki 27. örnekte olduğu gibi yine benzerlik fiilleri türeten ekiyle + sIn- ekiyle türemiş olan ve yine ilk olarak DLT'de geçen bu sözcük, Başkurtçada ek başında kurallı /s/ > /h/ değişimiyle ancak semantik bir değişime uğramaksızın günümüze kadar gelmiştir. Buna göre ET yersin- sözcüğü de Başkurtçanın tanıklığıyla hapax niteliğini yitiren veriler arasında yerini almaktadır.

29. ET yetizlik 'genişlik, uzunluk' (Clauson, 1972, s. 895a): Baş. yětěźlěk 'uzunluk' (Özşahin, 2017, s. 723).

Eski Türkçede ilk olarak DLT'de geçen ve yetiz 'enli, geniş' < (yet- II) (Clauson, 1972, $894 b$ ) isminden türemiş olan sözcük, Clauson tarafından hapax kaydıyla verilmiştir. Sözcüğün Başkurtça dengi Axmerov vd.'de yer almamakta; bu sözlükte sadece yětěź 'çevik, becerikli, 
hamarat' (1958, s. 187) gövdesi bulunmaktadır. DLT'de geçen yetizlik sözcüğü Başkurtçada Özşahin'in sözlüğü aracılığıyla yětěźlěk biçiminde tanıklanabilmekte ve DLT'ye ait bu veri hapax niteliğini yitirmektedir.

30. ET yıgım 'yığın' (Clauson, 1972, s. 903b): Baş. yıyım 'vergi, tahsilat' (Axmerov vd., 1958, s. 233), yıyım '1. tahsilat, vergi; 2. mahsul' (Özşahin, 2017, s. 734).

Eski Türkçe $y ı g$ - fiilinden -(I)m ekiyle türeyip ilk olarak DLT'de geçen bu sözcük, Başkurtçada iki ünlü arası - $\dot{g}$ - > $-y$ - gelişimiyle varlığını sürdürmektedir. Başkurtçada sözcüğün Eski Türkçe anlamı unutulmuş olup farklı bir anlamda kullanıldığı görülmektedir.

31. ET yıglış- 'toplaşmak' (Clauson, 1972, 903a): Baş. yıyılış- 'bir araya gelmek, toplaşmak' (Axmerov vd., 1958, s. 233), yıyılış- ‘bir araya gelmek, toplaşmak; grup oluşturmak' (Özşahin, 2017, s. 734).

Yine Eski Türkçe yıg- fiilinden edilgenlik ve işteşlik ekiyle türeyip ilk olarak DLT'de kaydedilen bu fiil, Başkurtçada iki ünlü arası $-\dot{g}->-y$ - gelişimiyle varlığını sürdürmekte ve hapax niteliğini yitirmektedir. Burada görüldüğü üzere ET yıglış- fiili hem 20. yüzyılın ilk yarısında hem de günümüz Başkurtçasında yıyılış- olarak tanıklanabilmiştir. Sözcügün Başkurtçada semantik değişime uğramadığı görülmektedir.

32. ET yunçıt- 'kötülük yapmak, zarar vermek' (Clauson, 1972, s. 945b): Baş. yonsot'yormak; eziyet çektirmek, bezdirmek, canını çıkarmak' (Axmerov vd., 1958, s. 227), yonsot'yorgunlaştırmak, yordurmak, bitap düşürmek, eziyet çektirmek' (Özşahin, 2017, s. 739).

Biri hariç buraya kadar ele alınan diğer sözcükler gibi Eski Türkçe döneminde ilk olarak DLT aracılığıyla tanıklanan bir diğer veri de yunçıt- sözcüğüdür. Clauson'un hapax olarak nitelendirdiği bu sözcük hem 20. yüzyılın ilk yarısında hem de çağdaş Başkurtçada yonsotbiçiminde tanıklanarak hapax niteliğini yitiren veriler arasında yerini almaktadır. Başkurtça fiil, semantik olarak DLT’deki anlamdan uzaklaşmamıştır.

\section{SONUÇ}

Bu incelemede Gerard Clauson'un Etimolojik Sözlük'ünde (1972) hapax kaydıyla verilen Türkçe kökenli söz varlığı ile Başkurtçanın söz varlığı karşılaştırılmıştır. Çalışmanın sonucunda, Clauson'un Kıpçak grubun geri kalanından çok fazla farklılaştığı için hiç değerlendirmeye almadığını belirttiği Başkurtçanın tanıklığıyla Eski Türkçe bagırlan-, bıçış-, bürçäklän-, bürgälän-, ärsäklän-, ätlä-, ttla-, isiglä-, kadışla-, karlan-, käçtür-, kıdıgla-, kutan-, küglänI, küzä-, örüm, talagu, tarmaklan-, tartışlıg, tayış-, tämürlük, tişät-, tüplän-, tüplät-, tüşlük, üklüş-, yazlat-, yemsin-, yersin-, yetizlik, yılıım, yıglış- ve yunçıt- sözcüklerinin hapax olmadığ 1 gösterilmiştir. Bu sözcüklerden bazıları Başkurtçayla birlikte birkaç Türk dilinde daha varlığını sürdürmektedir. Makalede üzerinde durulan 32 hapaxtan 17'sinin yani ıtla-, isiglä-, karlan-, küglän- I, küzä-, örüm, tarmaklan-, tämürlük, tişät-, tüplän-, tüplät-, tüşlük, üklüş-, yersin-, yılgım, yılglş̧- ve yunçıt- sözcüklerinin basım yılı itibarıyla Clauson'un yararlanmasının mümkün 
olduğu Axmerov vd.'nin (1958) sözlügü aracılığıyla tanıklanabildiği ortaya konmuştur. Etimolojik Sözlük'te hapax olarak verilen öteki 15 sözcüğ̈̈n ise Axmerov vd.'de (1958) yer almadığı ve yalnızca Özşahin' in çalışması (2017) aracılığıyla tanıklanabildiğine değinilmiştir. Bu nedenle Eski Türkçe için hapax kaydıyla verilen sözcüklerin Etimolojik Sözlük’ten sonraki metin yayınlarında ve Türk dillerine ait yeni sözlüklerde taranmaya devam edilmesi gerekmektedir.

Hakem Değerlendirmesi: Dış bağımsız.

Çıkar Çatışması: Yazar çıkar çatışması bildirmemiştir.

Finansal Destek: Yazar bu çalışma için finansal destek almadığını beyan etmiştir.

Peer-review: Externally peer-reviewed.

Conflict of Interest: The author has no conflict of interest to declare.

Grant Support: The author declared that this study has received no financial support.

\section{KAYNAKÇA/REFERENCES}

Ata, A. (2010). "Hapax in Rylands Manuscript Interlinear Translation of Koran into Turkic". International Journal of Central Asian Studies, 14: 1-12.

Ayazlı, Ö. (2018), “Tek Örnek Yundak Sözcüğü Üzerine”. Türk Dili Araştırmaları Yıllığ1-Belleten, 66/1: $151-163$

Axmerov, K. Z. ve diğer (1958). Başkirsko-russkiy slovar'. Moskva: Akademiya Nauk.

Clauson, G. (1972). An etymological dictionary of pre-thirteenth-century Turkish. Oxford: Oxford University Press.

Doğan, C. (2019). “Dîvânu Lugâti’t-Türk’teki Hapax Kelimelere Behcetü'l-Hadâyık’tan Tanıklar”. Yeni Türkiye, 105/1: 320-327.

Erdal, M. (1991). Old Turkic word formation I-II. Wiesbaden: Otto Harratsowitz.

Gültek, V. (2004). Rusça-Türkçe Sözlük. Ankara: Bilim ve Sanat.

Küçük, S., Demirci Ü. Ö. (2016). "Divânu Lugât'it-Türk’teki Hapaxlar -1-”. II. Uluslararsi Kaşkarli Mahmud Sempozyumu Bildiri Kitabı (21-23 Nisan 2016). Bişkek: 160-165.

Nadelyayev, V. M., Nasilov, D. M., Tenişev, E. R., Şçerbak A. M. (1969). Drevnetyurskiy slovar'. Leningrad: Nauka.

Ölmez, M. (2000). “Tuvacanın Eskiliği Üzerine”. Türk Dilleri Araştırmaları, 10: 133-138.

Ölmez, M. (2008). “Dīvānu Luġāti’t-Türk’teki Tek Örnekler Üzerine (1)”. Doğumunun 1000. Y11ı Dolayısıyla Uluslararası Kâşgarlı Mahmud Sempozyumu (17-19 Ekim 2008), Rize, Ed. Muhsin Kalkışım, Rize 2008.

Ölmez, M. (2011). “Tek Örnek’ Tek Örnek Değildir: Eski Türkçe üz ‘sağır’ Sözü Hakkında”. Maḥmūd al Kāşġari’nin 1000. Doğum Yıldönümü Dolayısıyla Uluslararası Divānu Luġāti’t-Türk Sempozyumu (5-7 Eylül 2008). İstanbul. Haz. Hayati Develi, Mustafa S. Kaçalin, Filiz Kıral, Mehmet Ölmez, Tülay Çulha (2011): 245-251.

Özşahin, M. (2017). Başkurt Türkçesi sözlüğü. Ankara: Türk Dil Kurumu.

Özşahin, M. (2020). “Başkurtçanın Sözlükleri”. Türk Dünyası Dil ve Edebiyat Dergisi, 50/2: 347-372. 
Pekarskiy, E. K. (1928). Slovar' Yakutskogo yazıka IV. Leningrad: Akademii nauk soyuza sovetskix sotsialistiçeskih sespublik.

Poppe, N. (1962). Bashkir manual, descriptive grammar and texts with a Bashkir-English glossary. Bloomington: İndiana University Uralic and Altaic Series, Volume 36.

Tenişev, E. R. (1968). Tuvinsko-russkiy slovar'. Moskova: Izdatelstvo Sovetskaya entsiklopediya.

Tezcan, S. (2008). "Dîvân Lugâti’t-Türk’te Tek Veriler (Hapax legomena)”. Doğumunun 1000. Y111 Dolayısıyla Uluslararası Kâşgarlı Mahmud Sempozyumu 17-19.1.2008 Rize. Bildiri Metinleri. Yayınlayan: M. Muhsin Kalkışım. Rize 2008. 298-302.

Türkçe Sözlük (2005). Ankara: Türk Dil Kurumu.

Uçar, E. (2012). “Eski Türkçe Hapaxlar”. Modern Türklük Araştırmaları Dergisi 9.1.: 73-100.

Wilkens, J. (2021). Handwörterbuch des altuigurischen. Altuigurisch-Deutsch-Turkish. Göttingen: Akademie der Wissenschaften zu Göttingen.

Yıldız, H. (2011). Yakutçayla tanıklanabilen hapax legomenon'lar. International Journal of Central Asian Studies, 15, 21-42.

Yıldız, H. (2014). Yakutçayla tanıklanabilen hapax legomenon'lar II: Ünsüzle başlayan hapaxların durumu. Siberian Studies, 2(5), 37-54. 